\title{
GROWTH RINGS IN A MONOCOTYL
}

\section{CONTRIBUTIONS FROM THE HULL BOTANICAL LABORATORY 285}

\author{
CHARLES J. CHAMBERLAIN
}

\section{(WITH SIXTEEN FIGURES)}

The principal object of this paper is to announce the discovery of growth rings in a monocotyl, but some observations upon growth rings in other plants may not be out of place. The most familiar example of periodic growth is seen in the annual rings of Gymnosperms and dicotyls; but even when there is a strong tendency to form only one ring every year, there are numerous variations, especially when the rings are very wide.

In Melia azedarach the annual rings are often more than a centimeter in width, but it is common to find in each season's growth a dozen or more secondary rings which are easily seen with the naked eye. The part of the ring formed in the spring and summer is quite sharply differentiated from that formed in the autumn, and it is in this autumn wood that the secondary rings are most conspicuous. In the spring and summer wood the few rather indefinite secondary rings are due to varying proportions of tracheae and tracheids. The tracheae of summer wood are not very different from those of early spring; while in the autumn wood the larger cells merely start to develop into tracheae. They have transverse walls, which in some cases begin to break down, but here the development ends. The tracheids of the autumn wood are numerous and very thick-walled, so that this part of the ring is extremely hard. It is evident that the secondary rings are due to periodic acceleration and retardation of growth, which causes them to show some of the features characteristic of ordinary annual rings.

Casuarina tenuissima affords another instance of numerous rings. A shoot about $3 \mathrm{~mm}$. in diameter and only a few weeks old showed five or six well marked rings, due to an alternation of tracheae and tracheids. The plant from which the shoot was taken was 
growing in the greenhouse, and the number of rings corresponds, roughly, to the number of times the plant was watered thoroughly. Several years ago, in the neighborhood of Jalapa, Mexico, where it is rather rainy throughout the year, a species of Piper was noticed which showed no growth rings; while the same species, a few miles farther east, where there is a sharp alternation of wet and dry seasons, showed the anticipated rings. These are examples of immediate response to rather slight changes in conditions. At the other extreme are plants which show no response to seasonal conditions, but nevertheless are susceptible to stronger stimuli.

Interesting growth rings which do not mark the number of years, but correspond to longer intervals, are found in the cycads. Dioon edule, after a period of coning or after damage by fire, loses all its leaves and goes into a prolonged resting stage which may last for several years. When it resumes activity and produces a new crown, a vigorous growth of wood takes place, with the formation of large tracheids, which, following the small tracheids of the nearly exhausted condition, produce a ring having the characters of an ordinary annual ring in Gymnosperms. These prolonged resting periods occur at long intervals, so that the number of rings would be of slight value in estimating the age of a plant. A section of the trunk of a specimen of D. edule I.5 to $2 \mathrm{~m}$. in height would enable one to estimate the interval between successive growth rings, since the approximate age of the plant could be determined; but at present it is not easy to secure such a section. In $D$. spinulosum the rings look like those of $D$. edule, but a ring is produced with the formation of every crown of leaves. Since crowns in this species are usually formed every other year, the number of rings indicates about half the age of the plant. In these cases the ring is a response to a change in conditions, but a very decided change is necessary to produce the result.

It has long been known that some arborescent monocotyls, like Dracaena, Yucca, and Aloe, produce a distinct zone of secondary tissue surrounding the primary and derived from a meristematic region showing the characters of cambium. In I912, while studying cycads in South Africa, I cut into a large plant of Aloe ferox 
to get material for demonstration purposes, and it was surprising to find growth rings so conspicuous that they could be seen where the stem was cut with an ax. Pieces to show both primary and secondary structures were preserved in formalin, and later Aloe pleuridens, A. ciliaris, and Dracaena Hookeriana were collected for comparison.

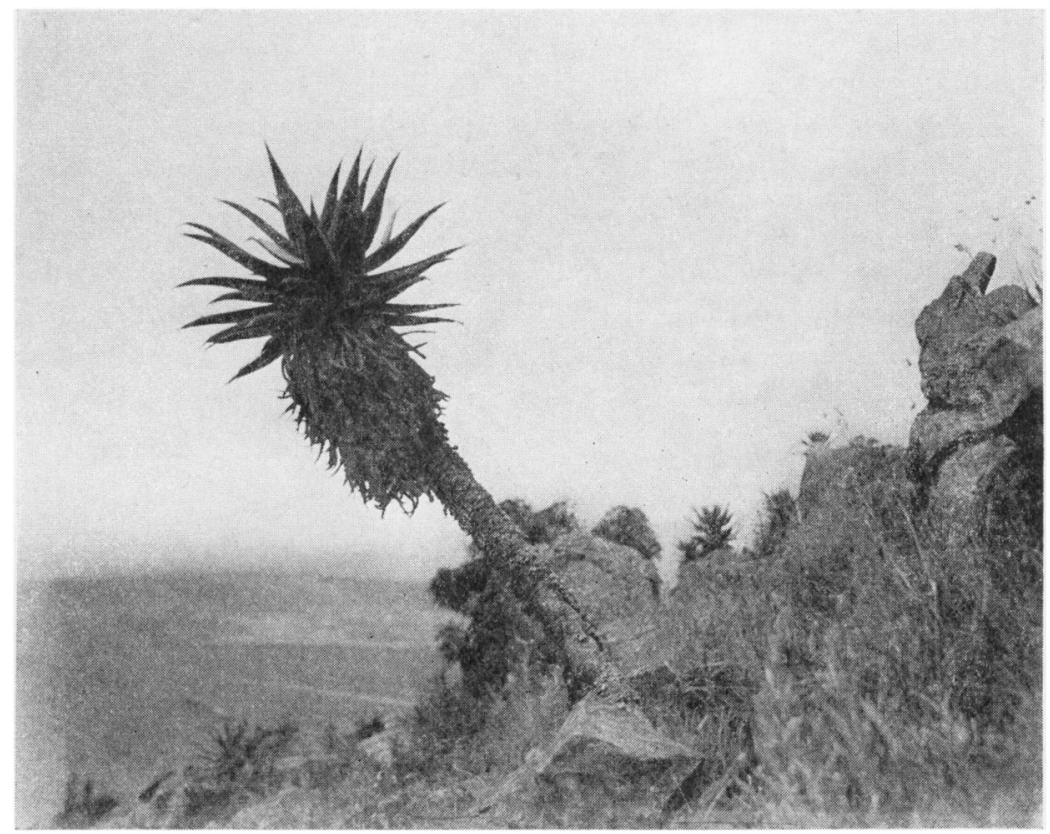
height.

Fig. I.-Aloe ferox at Cathcart, South Africa, January 1912; about $3 \mathrm{~m}$. in

Aloe ferox in the field presents a picturesque appearance, looking as if an Agave had developed a tall trunk (fig. I). It is associated with other xerophytic plants as bizarre as itself, among them tree forms of Euphorbia more than a dozen meters in height, species of Encephalartos, and others not so large but equally peculiar. Most of the material was collected near Grahamstown, South Africa, in January 1912 , from a stem $15 \mathrm{~cm}$. in diameter and about $3 \mathrm{~m}$. high. In transverse section the zone of secondary xylem 


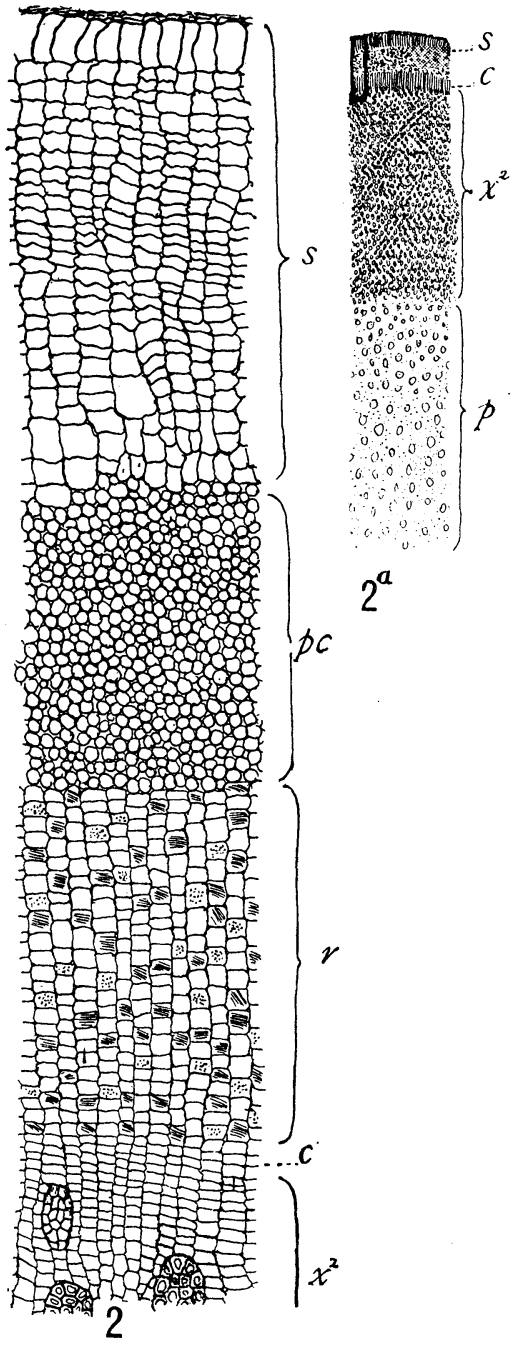

FIGS. 2, 2a.-Fig. 2, Aloe ferox, transverse section of part of stem: $s$, secondary cortex; $p c$, primary cortex; $r$, outer region of cells cut off by cambium and containing numerous raphides; $c$, cambium; $x^{2}$, region of secondary bundles from inner region of cells cut off by cambium; $\times 40$; fig. $2 a$, Aloe ferox: part of transverse section of stem, natural size; fig. 2 shows part included in rectangle at upper left corner: $s$, secondary cortex; $c$, cambium; $x^{2}$, region of secondary bundles; $p$, primary polystelic region. was $2 \mathrm{~cm}$. and the cortex $4 \mathrm{~mm}$. in width; so that the central region, nearly Io $\mathrm{cm}$. in diameter and consisting of primary structures, gave the whole section somewhat the appearance of a large pith surrounded by a narrow zone of wood and a scanty cortex.

The general topography of a small portion of a transverse section, natural size, is shown in fig. $2 a$. In the primary region $(p)$ the bundles are large and scattered, as in a cornstalk; while in the zone of secondary growth $\left(x^{2}\right)$ the vascular bundles are so regularly arranged, that to the naked eye they form a pattern like the chasing on a watch. The cambium (c), which is giving rise to secondary bundles, the secondary cortex $(s)$, and some of the primary cortex between these two zones of secondary growth, are also visible to the naked eye.

The phellogen, with the secondary cortex produced by it, the inner cambium with its derivatives, and also the primary cortex $(p c)$ between the two secondary products, are shown in fig. 2. The walls of the secondary cortex are 
slightly thickened, but thoroughly suberized. Beneath the secondary cortex is the primary, consisting of loose rounded cells with

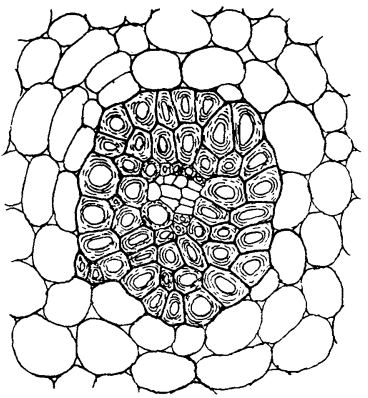

3
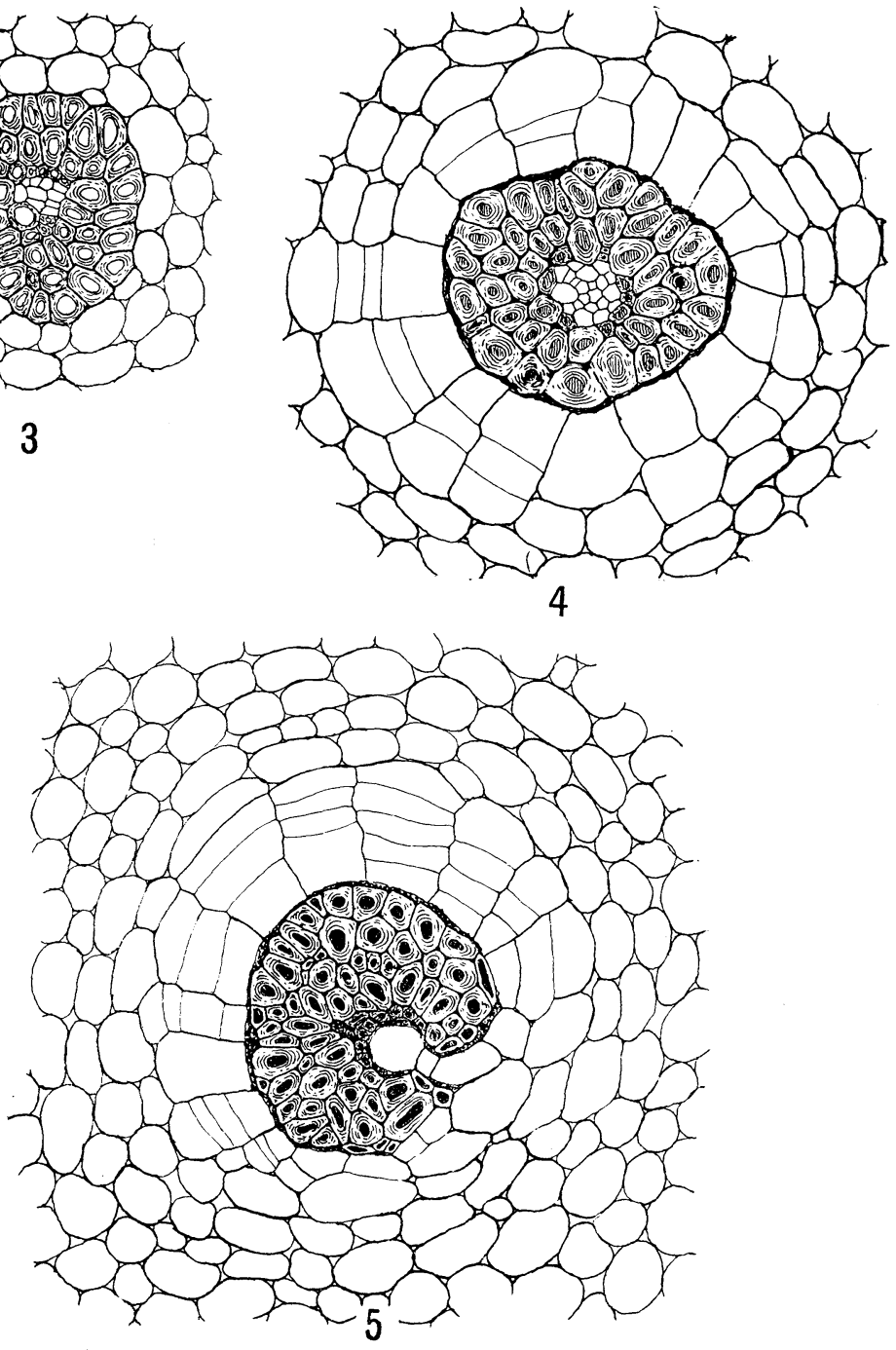

Figs. 3-5.-Fig. 3, Aloe ferox: normal bundle of primary polystelic region; $\times$ Ioo; fig. 4. Aloe ferox: bundle of primary polystelic region, showing clogged lumen of tracheids; some of cells immediately surrounding bundle becoming meristematic; $\times$ roo; fig. 5 , Aloe ferox: more advanced condition than in fig. $4 ; \times$ roo. 
cellulose walls, and between the primary cortex and the primary polystelic region is the zone which contains the secondary vascular bundles and shows the growth rings.

The primary polystelic region, in transverse section, looks somewhat like an immense cornstalk, with large bundles toward the center and smaller ones at the outside; but the structure of the individual bundles is very different from that in corn, for the bundles in Aloe have no sheath and most of them are completely amphivasal. There seem to be two types of vascular bundles in

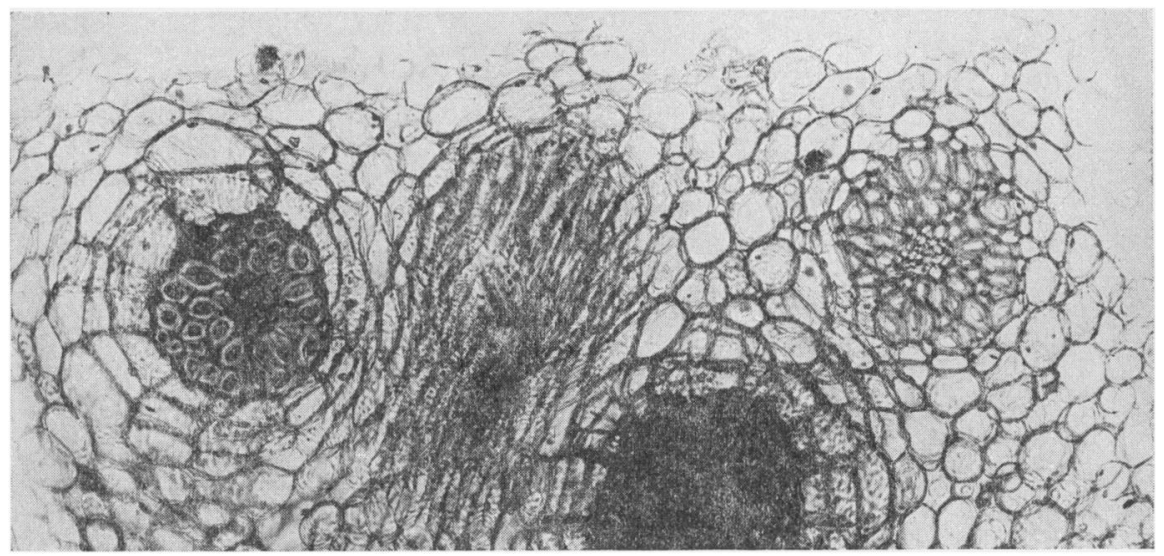

Fig. 6.-Aloe ferox: showing both types of primary bundles; $\times 100$

this primary region. In one type the bundles have normal xylem and phloem, except that the phloem has very few companion cells (fig. 3). The other type is peculiar. The phloem begins to disorganize and finally disappears, while the lumen in both tracheids and vessels becomes clogged with the same material found in the disorganizing phloem. Some of this material can also be seen surrounding the bundle itself. An early stage, shown in fig. 4, and a later stage, shown in fig. 5, are characteristic. In the latter figure the contents of the xylem cells are much denser and the phloem cells have become almost indistinguishable, while the adjacent thin-walled parenchyma is crowding into the space left vacant by the disorganizing phloem. 
Another peculiar feature of the bundle with disorganizing phloem is the appearance of vigorous meristematic activity in the cells surrounding the xylem. These cells behave like a cambium, so that rows consisting of as many as eight cells may be formed (figs. 4, 5). If differentiation should take place, we should expect to find a xylem zone and, perhaps, phloem surrounding the primary bundle; but development stops soon after the stage shown in fig. 5 , before any lignification can be detected. The distribution and general appearance of the primary bundles are shown in fig. 6 .

That the secondary growth in some monocotyls, like Yucca, Dracaena, and Aloe, results from meristematic activity is well known. The piece of a transverse section of Aloe ferox, natural size (fig. 2a), already referred to, and a somewhat magnified view of the origin of secondary structures (fig. 2), show the position of the structures to be described. The phellogen is evidently hypodermal in origin, and it builds up a
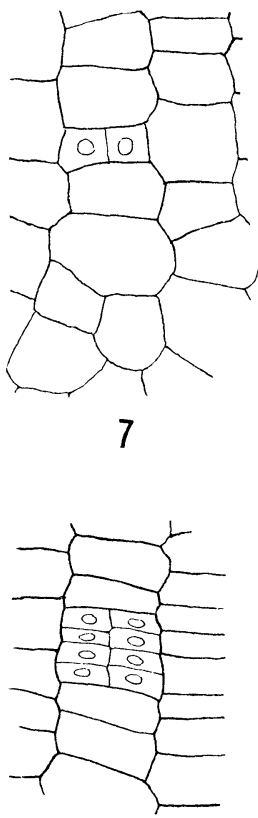

9

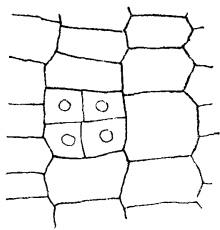

8

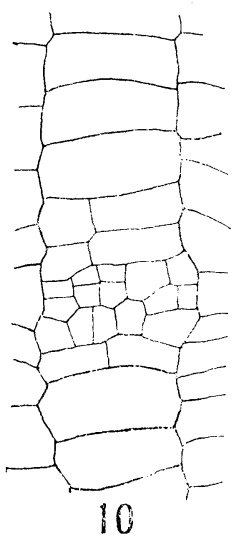

Figs. 7-ro.-Aloe pleuridens: four early stages in development of secondary bundle; $X$ Ioo.

limited amount of secondary cortex, with rectangular cells in regular rows abutting upon the smaller spherical cells of the primary cortex. The cambium which gives rise to the vascular structures is pericyclic in origin, and, as seen in transverse section, gives rise to long rows of cells. The cells on the outer side of the cambium undergo comparatively little differentiation; they enlarge to about twice the size of the cambium cells, and many of them become almost entirely filled with needle-shaped crystals of calcium 

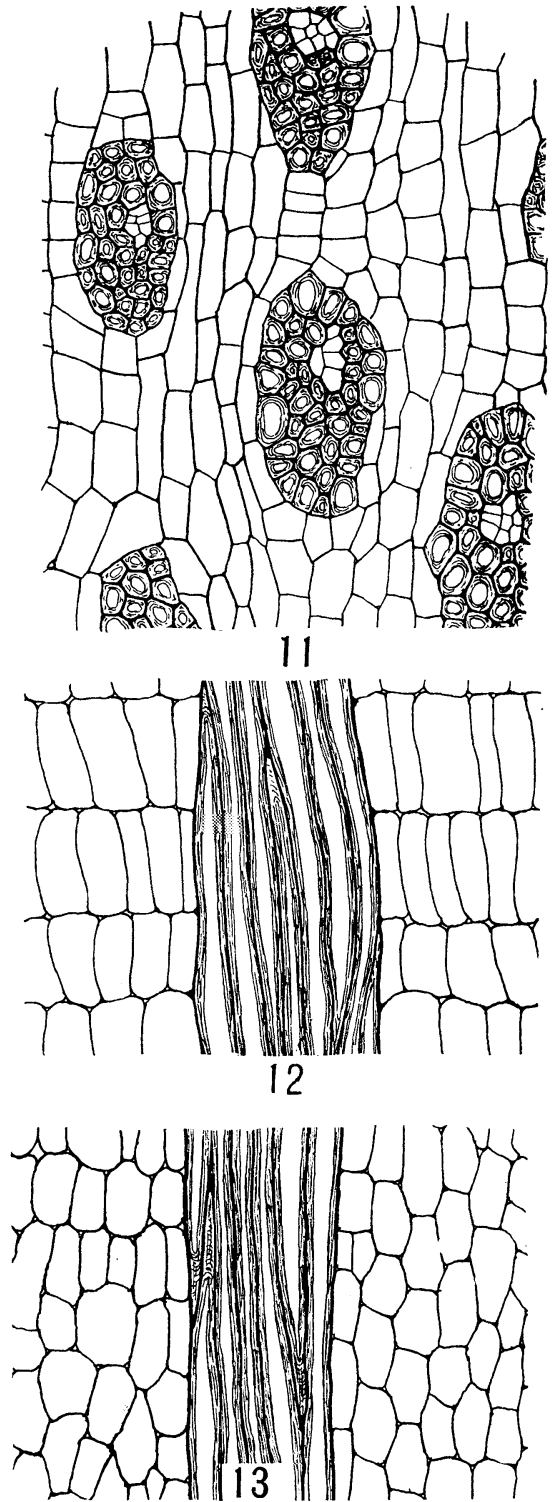

Figs. II-I3.-Aloe ferox: fig. II, transverse section of secondary bundle; fig. I2, longitudinál radial section; fig. I3, longitudinal tangential section; $\times$ ıо०. oxalate; but the cell walls thicken very little and retain the cellulose reaction (fig. $2 r$.)

The cells formed centripetally from the cambium give rise to the secondary woody structures which show the growth rings. The development of the bundle was not studied very thoroughly in Aloe ferox, but the early stages are about the same as in $A$. pleuridens. As seen in transverse section, a cell of the row produced by the cambium divides, the two resulting cells divide, and the process continues until forty or fifty cells are formed (figs. 7-10). Differentiation of the young cells of the vascular strand begins to take place before the full number of cells has been reached. These bundles are completely amphivasal and there is no sheath of thick-walled cells. The phloem is scanty and companion cells are rare. There is no degeneration or clogging of the lumen in the secondary bundles, and there is no meristematic activity in any of the surrounding cells, like that which characterizes many of the bundles of the primary cylinder. Since the 
bundle is completely amphivasal, there is no cambium between the xylem and phloem, like that found in the primary bundles of many monocotyls (fig. II).

The xylem consists almost entirely of tracheids with bordered pits and with walls so thick and hard that sectioning is difficult. The cells cut off from the inner side of the cambium and not taking part in the formation of the bundles keep, more or less perfectly, their linear arrangement. They are short, somewhat rectangular in radial view, and are arranged in very definite rows (fig. I2). The tangential arrangement is not so regular (fig. I3). While they thicken only a little, they become thoroughly lignified and extremely hard, so that they add to the difficulty of cutting sections. They are marked by numerous small simple pits.

The growth rings constitute the most striking feature of the stem. DE BARY, in his Comparative anatomy of vege-

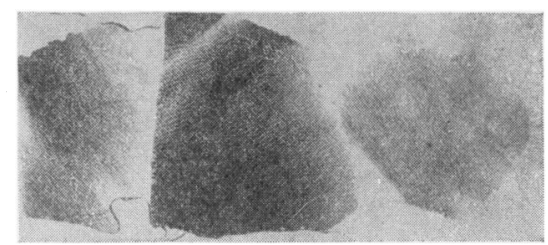

FIG. I4.-Aloe ferox: three thick transverse sections of stem; natural size.

tative organs of the phanerogams and ferns, remarked that, while there seemed to be no reason why growth rings should not be formed in woody monocotyls, none had ever been observed. An examination of the literature of vascular anatomy failed to yield any account of such rings; but, to make certain that nothing had been overlooked, I wrote to Professor Jefrrey, and he not only informed me that such rings had never been reported, but also gave some suggestions which greatly facilitated the investigation.

To the naked eye the growth rings are obvious, but under a I $6 \mathrm{~mm}$. objective no one would suspect their presence. In Dioon, where growth rings are obvious to the naked eye but not so conspicuous under the microscope, the rings are due to the fact that cells formed at the close of a growth period are somewhat smaller and have thicker walls than those formed when growth is resumed. In Aloe ferox the explanation is not so evident. An examination of fig. I4, showing three thick transverse sections, indicates that the rings can be seen, even in a half-tone reproduction. 
The rings can be seen more clearly by looking across the figure from nearly the level of the paper. The negative was made twice the size of the section, and the illustration reduced to natural size. The same sections without reduction are shown in fig. I5. The appearance, under a low magnification, is shown in fig. I6, which includes six of the growth rings. The rings are not at all conspicuous, and the number of rings probably could not be counted in the illustration. Even with the position on the rings marked with the numerals $\mathrm{I}-6$, they are not easily identified. Two structural features cause a ring. At the close of the growing period a few

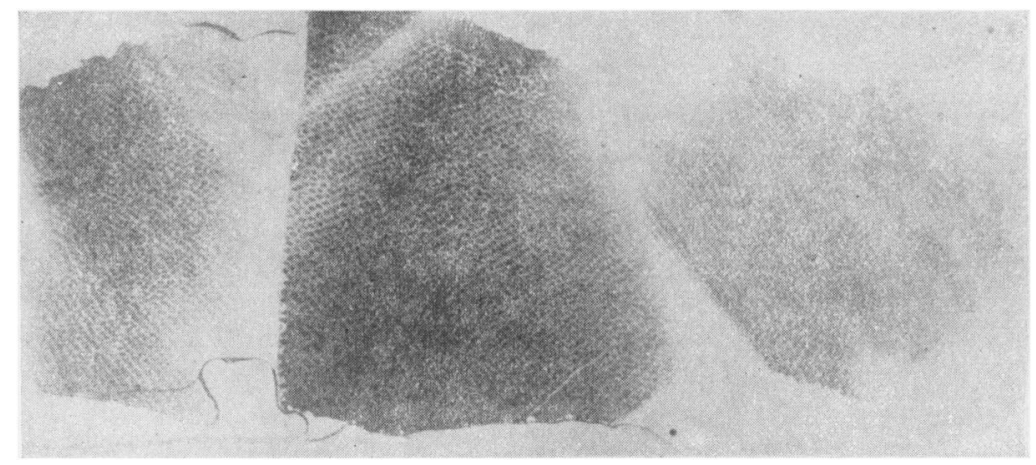

FIG. 15.-Aloe ferox: from same negative as fig. $14 ; \times_{2}$

smaller bundles at irregular intervals are probably responsible, but the principal cause is that the parenchyma cells formed at the close of a growing period are slightly smaller and have slightly thicker walls.

I wrote to Professor SchönLAND, Director of the Albany Museum at Grahamstown, South Africa, and to Mr. E. E. GAlpIN, formerly of Queenstown but now of Naboomspruit, Transvaal, South Africa, inquiring about climatic conditions in the localities from which the material was secured. Professor ${ }^{-}$SchöNLAND, to whom I am also indebted for material of Aloe ferox, wrote as follows:

There are two maxima of rainfall, in October and November, and in March and April; but this comes out only when the averages of a number of years are worked out and give a wrong picture of the relation of the flora to our rainfall. It is true that the winter, from the middle of June to the middle of September, is generally dry; but I have known good rains in these three months. Last year ( 1920$)$ the October-November rains failed us; we had 
good rains at Christmas, then drought to the middle of March, and then good soaking rains. The yearly amount of rainfall is often very interesting. In 1899 we had a serious drought up to Christmas, and then 12 inches in 24 hours. The long and short of it is that we live in what might be called the fag end of the summer rain area; but it can best be described as an area of uncertain rains.

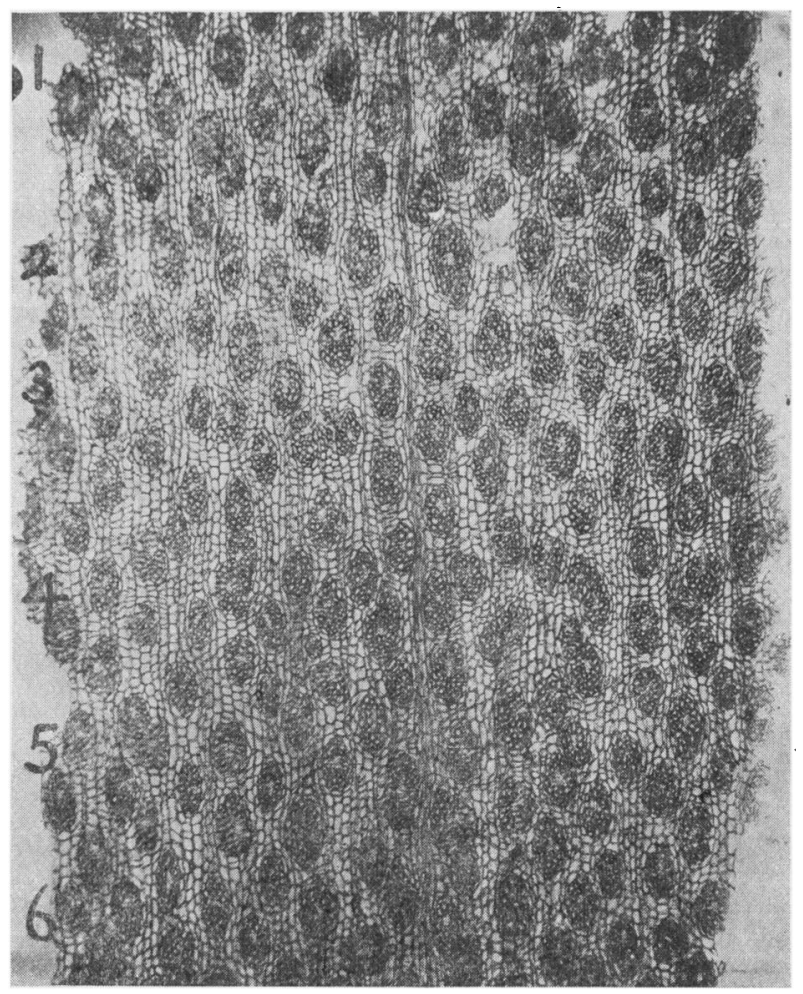

FIG. r6.--Small portion of region of secondary bundles, including six growth rings, numbered $\mathrm{I}-6 ; \times$ I0.

\section{Mr. Galpin replied as follows:}

Around Grahamstown and the coastal districts generally, the seasons are very equitable, with no winter frosts and the rainfall fairly equally distributed throughout the year. Like the whole of South Africa, they have their lean years and their fat years, with deficient or generous rainfall, as the case may be. Added to this, at long but irregular intervals, perhaps a quarter of a century, more or less, for reasons as yet quite unexplained, there may come a period of prolonged drought or of exceptional rains. These remarks apply to Cathcart as well, but in that district, with an altitude of about $4000 \mathrm{ft}$., the seasonal changes are greater, with hot summers and frosty nights in winter. 
The rainfall is also very much greater in summer than in winter, although the difference between dry and wet seasons is not so marked up here, nearer the tropics. They get a certain amount of rain during the winter months, while at Naboomspruit, with an annual rainfall of 25 inches, usually not a drop falls from the end of April to the beginning or even the end of October.

These two accounts, written by botanists who have made a prolonged study of the South African flora, show that the climatic conditions in the region where Aloe ferox grows are somewhat erratic. Large specimens were seen at Junction Farm in the Transkei, near Cathcart, and the negative from which fig. I was made was taken on the Windvogelberg, overlooking the town of Cathcart; but no material was collected. Judging from Mr. GALPIN's account, specimens from the Windvogelberg would show more sharply marked rings than one would be likely to find in plants from the Grahamstown region where this material was collected. Both accounts, however, would lead one to expect the irregularities which appear in the rings of material collected near Grahamstown. Irregularities may be seen in figs. I4 and I5, and in fig. I6, where the position of the six rings is marked by the numerals $\mathrm{I}-6$.

Whether other species of Aloe would show rings or not could be determined very easily by one who is within reach of material. A few slides of $A$. pleuridens show a couple of faint rings. Dracaena Hookeriana, collected at East London, less than Ioo miles south of Cathcart, shows secondary wood but no growth rings. It would be interesting to see the condition in Aloe Bainesii, the trunk of which may reach a diameter of a meter in less than thirty years. A specimen of $Y u c c a$ with a zone of wood a centimeter in diameter, growing in the greenhouse, showed no growth rings; but such rings could hardly be expected in a greenhouse, where conditions are so uniform. One wonders whether the failure to find growth rings in woody monocotyls may not be due to the fact that they are mostly tropical and subtropical, out of the University zone, so that observations are likely to have been made upon greenhouse material. That there are growth rings in Aloe ferox is beyond question, and this is believed to be the first account of such rings in any monocotyl.

University of ChicAgo 